\title{
Higher arterial pressure during cardiopulmonary bypass may not reduce the risk of acute kidney injury
}

\author{
Kristian Kandler $^{1 *}$ (D) Jens C. Nilsson², Peter Oturai ${ }^{3}$, Mathias E. Jensen $^{1}$, Christian H. Møller ${ }^{1}$, Jens Otto Clemmesen ${ }^{4}$,
} Henrik C. Arendrup ${ }^{1}$ and Daniel A. Steinbrüchel ${ }^{1}$

\begin{abstract}
Background: Acute kidney injury after cardiac surgery is common and associated with increased mortality. It is unknown whether an intended higher arterial pressure during cardiopulmonary bypass reduces the incidence of acute and chronic kidney injury.

Methods: Patients were randomised either to a control group or a high pressure group (arterial pressure $>60 \mathrm{mmHg}$ ). The inclusion criteria were age $>70$ years, combined cardiac surgery and serum creatinine $<200 \mu \mathrm{mol} / \mathrm{L}$. Glomerular filtration rate using the Cr-EDTA clearance method was measured the day before surgery and 4 months postoperatively. The RIFLE criteria were used to define the presence of acute kidney injury. In addition, the ratio between urinary Neutrophil Gelatinase-Associated Lipocalin (NGAL) and creatinine was measured.

Results: Ninety patients were included. Mean age was $76 \pm 4$ years and $76 \%$ were male. Mean arterial pressure was $47 \pm$ $5 \mathrm{mmHg}$ in the control group and $61 \pm 4 \mathrm{mmHg}$ in the high pressure group $(p<0.0001)$. The change in glomerular filtration rate at follow-up was $-9 \pm 12 \mathrm{ml} / \mathrm{min}$ in the control group and $-5 \pm 16 \mathrm{ml} / \mathrm{min}$ in the high pressure group $(p=$ $0.288,95 \% \mathrm{Cl}-13$ to 4$)$. According to the RIFLE criteria 38\% in the control group and $46 \%$ in the high pressure group developed acute kidney injury ( $p=0.447$ ). The postoperative urinary NGAL/creatinine ratio was comparable between the groups.
\end{abstract}

Conclusions: An intended increase in arterial pressure during cardiopulmonary bypass to $>60 \mathrm{mmHg}$ did not decrease the incidence of acute or chronic kidney injury after cardiac surgery.

Trial registration: Clinicaltrials.gov, identifier: NCT01408420. Registered 3rd of August 2011.

Keywords: Acute kidney injury, Arterial pressure, Cardiac surgery

\section{Background}

Acute kidney injury (AKI) is a well-known complication to cardiac surgery and is associated with increased mortality [1-6]. The reported incidences range from 1 to $56 \%$ in the literature [7-9].

The etiology behind the development of AKI after cardiac surgery is incompletely understood and probably multifactorial. Possible contributing factors include systemic inflammatory response, microemboli and haemodilution. Some studies have also indicated that the use of a heart-lung

\footnotetext{
*Correspondence: kristian.kandler@regionh.dk; kristiankandler@gmail.com ${ }^{1}$ Department of Cardiothoracic Surgery, Copenhagen University Hospital, Rigshospitalet, Blegdamsvej 9, 2100 Copenhagen, Denmark Full list of author information is available at the end of the article
}

machine versus off-pump beating heart surgery increases the risk of AKI [10-12].

Furthermore, the management of flow and arterial pressure $(\mathrm{AP})$ during cardiopulmonary bypass $(\mathrm{CPB})$ is not evidence based [13]. It has been shown in a previous study that a prolonged duration with an $\mathrm{AP}<60 \mathrm{mmHg}$ during $\mathrm{CPB}$ increases the risk of AKI [14]. The range of renal autoregulation has been found to be between $75 \mathrm{mmHg}$ and $160 \mathrm{mmHg}$ in an experimental setting [15]. During $\mathrm{CPB}$ the $\mathrm{AP}$ is below this range the majority of the time. Furthermore, the pressure during $\mathrm{CPB}$ is continuous and not pulsatile as under normal conditions and the pressure spikes of the systolic blood pressure are not present. Therefore, when outside of the autoregulatory range of

(c) The Author(s). 2019 Open Access This article is distributed under the terms of the Creative Commons Attribution 4.0 International License (http://creativecommons.org/licenses/by/4.0/), which permits unrestricted use, distribution, and 
the kidneys, a higher-than-spontaneous AP during $\mathrm{CPB}$ may improve renal microcirculation and decrease the risk of AKI. In addition, it is unknown whether there is a correlation between AKI and chronic kidney injury after cardiac surgery.

The hypothesis of this study is that an intended high AP during $\mathrm{CPB}$ decreases the incidence of acute and chronic kidney injury in a population highly predisposed to AKI.

\section{Methods}

Ninety patients were enrolled in the study between May 2011 and December 2013 (clinicaltrials.gov identifier: NCT01408420). All patients were operated at Rigshospitalet, Copenhagen University Hospital, Copenhagen, Denmark. The study was approved by The Regional Committee on Biomedical Research Ethics. Written informed consent was received from all patients prior to their inclusion in the study.

\section{In- and exclusion criteria}

To ensure that the cohort had a high preoperative risk of developing AKI, the inclusion criteria were age $>70$ years and complex cardiac surgery procedures (heart valve and bypass surgery in combination). Exclusion criteria were serum creatinine $(\mathrm{sCr})>200 \mu \mathrm{mol} / \mathrm{L}$, previous heart surgery, endocarditis and acute operation defined as coronary angiography $<24 \mathrm{~h}$ of surgery.

\section{Randomisation}

A parallel-group study was conducted where patients were randomised into either a control group (CG) or a high pressure group (HPG) using closed opaque envelopes that were sequentially numbered. The allocation ratio was 1:1. Randomisation was performed the day before surgery after informed consent. The patients and outcome assessors who analysed GFR, blood- and urine samples were blinded until follow-up. The generation of the random allocation sequence, the randomisation and enrolment of patients were done by the first author of this paper.

\section{Anaesthesia}

Patients were premedicated with triazolam $0.125-0.250$ mg orally 1 hour prior to surgery. Anaesthesia was induced with fentanyl $(10 \mu \mathrm{g} / \mathrm{kg})$, propofol $(1-2 \mathrm{mg} / \mathrm{kg})$ and cisatracurium $(0.1 \mathrm{mg} / \mathrm{kg})$. Maintenance of anaesthesia was achieved using sevoflurane $(0.5-3 \%)$ and continuous infusion of remifentanil (15 to $30 \mu \mathrm{g} / \mathrm{kg} / \mathrm{hour}$ ). Intravenous administration of $1500 \mathrm{mg}$ of cefuroxime and a single-shot of $240 \mathrm{mg}$ of gentamicin were given after induction of anaesthesia. No specific guidelines were used in regards to the administration of the singleshot gentamicin. AP was recorded through a cannula placed in the radial artery.
After heparinisation ( $350 \mathrm{IU} / \mathrm{kg}$, ACT $>480 \mathrm{~s})$, normothermic $\mathrm{CPB}\left(36.5-37.0^{\circ} \mathrm{C}\right.$ bladder temperature) was initiated as follows: in the ascending aorta an angled arterial cannula was placed (DLP 24 FR, Medtronic, Minneapolis, Minnesota) and a two-stage venous cannula (36/46 FR, Medtronic) was inserted through the right atrial appendage. A membrane oxygenator (Capiox RX25, Terumo, Tokyo, Japan) and a roller pump (Stockert S5, Sorin Group, Milano, Italy) were used for perfusion with nonpulsatile flow. The arterial line included a $40-\mu \mathrm{m}$ filter (AL06, Pall, Port Washington, New York). Pump flow was calculated by multiplying $2.4 \mathrm{~L} /$ minute by the body surface area in square metres.

Intraoperative $\mathrm{CPB}$ data were retrieved from electronic perfusion charts. The AP during CPB was sampled electronically every minute by the heart-lung machine. The average AP during $\mathrm{CPB}$ was calculated using the values from clamping to de-clamping of the ascending aorta.

\section{Endpoints}

The primary end-point of this study was mean change in glomerular filtration rate (GFR) at follow-up compared to baseline.

The secondary end-point were change in urinary Neutrophil Gelatinase-Associated Lipocalin (uNGAL) and urinary creatinine ratios at different postoperative timepoints compared to baseline, a method that has been shown to be highly sensitive in predicting AKI [16].

It was not possible to calculate sample size since no data on ${ }^{51} \mathrm{Cr}$-ethylenendiaminetetra acetic acid plasma clearance technique (Cr-EDTA) GFR measurements existed on cardiac surgery patients at the initiation of the study.

Baseline $\mathrm{u}$-NGAL and urine creatinine were measured using urine samples taken just after induction of anaesthesia and insertion of a urinary catheter. Postoperatively the samples were taken at arrival to the intensive care unit (ICU) and 6-, 18-, 48- and $120 \mathrm{~h}$ postoperative. The samples were centrifuged for $5 \mathrm{~min}$ at $1000 \mathrm{RPM}$ and the supernatant was pipetted into cryotubes. The cryotubes were placed in a freezer at -80 degrees Celsius for a maximum of 9 months before analysis, a period that has previously been found to be safe for storing UNGAL [17]. The urine samples were analysed for uNGAL using the NGAL Test reagent kit (BioPorto Diagnostics, Gentofte, Denmark) on a Cobas c501 analyser (Roche, Basel, Switzerland) using fully automated particle-enhanced turbidimetric immunoassay. On the same analyser urine creatinine levels were measured to adjust for postoperative hydration status using the Creatinine Plus version 2 reagent kit (CREP 2, Roche, Basel, Switzerland).

GFR was measured by the ${ }^{51} \mathrm{Cr}$-ethylenendiaminetetra acetic acid (EDTA) plasma clearance technique the day before surgery and 4 months postoperative [18]. Four 
plasma samples were collected during 60 min within the period of three to 5 hours after tracer injection.

Baseline $\mathrm{sCr}$ values were defined as the preoperative value closest to the day of surgery. Postoperative $\mathrm{sCr}$ samples were taken in the morning of the first and second postoperative day. The patients were characterised as either AKI or no-AKI based on the RIFLE criteria. AKI was present when an increase in $\mathrm{sCr}$ values of $>50 \%$ or absolute increase of $>27 \mu \mathrm{mol} / \mathrm{l}$ occurred within the first $48 \mathrm{~h}$ postoperative, compared to baseline. An estimated GFR (eGFR) was calculated based on $\mathrm{sCr}$ using the CockroftGault formula. In accordance with the RIFLE criteria an eGFR decrease of $>25 \%$ was also used to define AKI.

\section{Intervention}

In the CG the patients underwent standard anaesthesia and $\mathrm{CPB}$ with the exception of a maximum of $110 \%$ flow on the heart-lung machine.

In the HPG an infusion containing isotonic sodium chloride and norepinephrine was mixed according to patient weight so that $1 \mathrm{ml} /$ hour equalled $0.01 \mu \mathrm{g} / \mathrm{kg} / \mathrm{min}$ of norepinephrine. This mixture was used when the AP was $<60 \mathrm{mmHg}$ during $\mathrm{CPB}$. If the target pressure could not be reached the infusion rate was not increased above $30 \mathrm{ml} /$ min. Maximum flow on the heart-lung machine was $110 \%$.

\section{Statistics}

The study was conducted on an intention-to-treat basis.

Continuous data are presented as means \pm standard deviations (SD) or median (interquartile range). Continuous variables were compared by Student's unpaired $t$-test; categorical variables were compared by Pearson's chi-squared test. Mann-Whitney U-test was used to compare $\mathrm{sCr}$ levels between the groups and u-NGAL/ creatinine ratios between the groups at each time-point after correcting for the preoperative measurement. Paired samples $t$-test was used to compare preoperative GFR, eGFR and sCr with values at follow-up.

Differences were considered to be statistically significant when the $p$ value was $<0.05$.

Statistical analysis was performed using the statistical software package SPSS, version 22.0.0.0; SPSS Inc.; Chicago IL.

\section{Results}

Ninety patients were included from May 2011 to October 2013. Last patient follow-up was done January 2014. Mean age was $76 \pm 4$ years and $76 \%$ were male.

No differences in preoperative data were found between the groups (Table 1). Intraoperative data were comparable between the groups except the AP, which was $47 \pm 5 \mathrm{mmHg}$ and $61 \pm 4 \mathrm{mmHg}$ in the $\mathrm{CG}$ and HPG, respectively $(p<0.001)$ (Table 2$)$. Postoperative data, including short- and medium term survival,
Table 1 Preoperative data

\begin{tabular}{lllll}
\hline & CG & HPG & $p$ value & $95 \% \mathrm{Cl}$ \\
\hline $\mathrm{N}$ & 45 & 45 & - & \\
Male gender & $33(73 \%)$ & $32(71 \%)$ & 0.450 & \\
Age (years) & $76.3 \pm 4.2$ & $76.6 \pm 4.7$ & 0.731 & -2 to 2 \\
BSA (m ${ }^{2}$ & $1.93 \pm 0.19$ & $1.91 \pm 0.18$ & 0.611 & -0.07 to 0.10 \\
BMI (kg/m $\left.{ }^{2}\right)$ & $26.5 \pm 3.70$ & $27.2 \pm 4.70$ & 0.519 & -2.5 to 1.1 \\
EuroSCORE II & $3(2-5)$ & $3(3-5)$ & 0.264 & -1 to 1 \\
Hypertension & $31(80 \%)$ & $26(68 \%)$ & 0.268 & \\
COPD & $2(5 \%)$ & $0(0 \%)$ & 0.157 & \\
NIDDM & $3(8 \%)$ & $8(21 \%)$ & 0.094 & \\
IDDM & $2(5 \%)$ & $3(8 \%)$ & 0.622 & \\
PAD & $7(18 \%)$ & $3(8 \%)$ & 0.189 & \\
CD & $6(15 \%)$ & $5(13 \%)$ & 0.780 & \\
GFR (ml/min) & $77 \pm 21$ & $69 \pm 28$ & 0.142 & -3 to 19 \\
sCr ( $\mu \mathrm{mol} / \mathrm{dl})$ & $88(80-101)$ & $84(69-116)$ & 0.452 & -18 to 12 \\
eGFR (ml/min) & $72 \pm 22$ & $71 \pm 29$ & 0.966 & -11 to 11 \\
\hline Percentages a & & & \\
\hline
\end{tabular}

Percentages are given as total within group. Continuous data are presented as mean \pm SD or median (interquartile min - max)

$B S A$ Body surface area, $B M I$ Body mass index, $C l$ confidence interval, $C O P D$ Chronic Obstructive Pulmonary Disease, IDDM Insulin-Dependent Diabetes Mellitus, NIDDM Non-Insulin-Dependent Diabetes Mellitus, PAD Peripheral Arterial Disease, $C D$ Cerebral disease, eGFR Estimated glomerular filtration rate (calculated using the Cockroft-Gault formula), GFR Glomerular filtration rate (estimated by $\mathrm{Cr}$-EDTA clearance), sCr Serum creatinine

incidence of acute kidney injury and GFR were equal between the groups (Table 3).

Forty-eight patients completed follow-up (25 patients in the CG and 23 in the HPG). Six (7\%) patients died inhospital (three patients in each group). Nine patients (10\%) died after discharge but before follow-up (4 patients in the CG group and 5 patients in the HGP group). Four (4\%) patients declined to continue in the trial in the immediate postoperative period (two in each group). The actual follow-up rate was therefore 48 out of 71 patients (68\%). Time of follow-up was $4.1 \pm 1.5$ months.

The secondary outcomes were analysed in all $90 \mathrm{pa}-$ tients. A participant flow diagram is presented in Fig. 1.

\section{Glomerular filtration rate}

For the total patient group a significant decline in GFR following cardiac surgery was observed.

Preoperative and postoperative GFR was $78 \pm 27 \mathrm{ml} /$ $\min$ and $70 \pm 26 \mathrm{ml} / \mathrm{min}$, respectively $(p=0.001)$. The GFR change from baseline to follow-up did not differ between the two groups, $-9 \pm 12 \mathrm{ml} / \mathrm{min}$ in the CG and $-5 \pm 16 \mathrm{ml} / \mathrm{min}$ in the HPG $(p=0.288)$ (Table 3).

Eleven patients (44\%) in the CG and 9 (39\%) in the HPG had a GFR drop of $>10 \%$ at follow-up compared to baseline $(p=0.732)$. At follow-up 9 patients $(36 \%)$ in the CG group and $5(22 \%)$ in the HPG had a GFR drop of $>20 \%(p=0.278)$. 
Table 2 Intraoperative data

\begin{tabular}{lllll}
\hline & CG & HPG & $p$ value & 95\% Cl \\
\hline AP $(\mathrm{mmHg})$ & $47 \pm 5$ & $61 \pm 4$ & 0.001 & -15 to -11 \\
Flow $(\mathrm{L} / \mathrm{min} / \mathrm{m} 2)$ & $2.6 \pm 0.2$ & $2.6 \pm 0.2$ & 0.810 & -0.1 to 0.1 \\
CABG + AVR & $38(84 \%)$ & $36(80 \%)$ & 0.415 \\
CABG + MVR & $4(9 \%)$ & $8(18 \%)$ & 0.290 \\
AVR + MVR & $1(2 \%)$ & $0(0 \%)$ & 0.314 \\
CPB time (min) & $130 \pm 36$ & $130 \pm 31$ & 0.994 & -30 to 19 \\
XC time (min) & $100 \pm 39$ & $93 \pm 22$ & 0.310 & -19 to 12 \\
Blood loss (ml) & $636 \pm 482$ & $667 \pm 397$ & 0.759 & -222 to 153 \\
Diuresis (ml) & $517 \pm 294$ & $639 \pm 438$ & 0.152 & -299 to 15 \\
Change in HCT (\%) & $-8 \pm 5$ & $-7 \pm 4$ & 0.069 & -4 to 0 \\
Fluid balance (ml) & $1490 \pm 1206$ & $1246 \pm 968$ & 0.327 & -382 to 753 \\
Gentamicin administered & $31(78 \%)$ & $32(80 \%)$ & 0.353 & \\
\hline
\end{tabular}

Percentages are given as total within group. Continuous data are presented as mean \pm SD

$A P$ Arterial pressure, AVR Aortiv valve replacement, $C l$ confidence interval, CPB Cardiopulmonary bypass, $H C T$ Haematocrit, $M V R$ Mitral valve replacement, XC Aortic cross clamp

\section{Acute kidney injury}

The uNGAL/creatinine ratio was not significant between the two groups at any time-point (Table 4).

$35(41 \%)$ of the patients developed AKI according to the RIFLE criteria. No significant differences were found in the incidence of AKI between the groups which was $16(38 \%)$ and $19(46 \%)$ in the CG and HPG respectively $(p=0.447) .7$ patients received renal replacement therapy during the hospital stay of which 4 (9\%) were in the CG and $3(7 \%)$ in the HPG $(p=0.565)$

Among AKI patients, 12 out of 17 (71\%) had a decrease in GFR $>10 \%$ at follow-up. In patients who did not develop AKI 8 out of 31 (26\%) patients had a GFR decrease $>10 \%$. The difference in proportion of patients with a GFR decrease $>10 \%$ were statistically significant between AKI and no-AKI patients $(p=0.003)$.

The results of a sub-analysis comparing patients who develop AKI with patients who do not develop AKI looking at specific risk factors are presented in Table 5. No significant risk factors of AKI were identified.

Cause of death after discharge but before follow-up was cardiac related death in three patients and one patient in the CG and HPG, respectively. One patient in each group died from infection. One patient in the $C G$ died from intracerebral haemorrhage. Dehydration and cancer was the cause of death in two patients in the HPG. No patients that died before follow-up were in the need of dialysis. No significant difference in the cause of

Table 3 Postoperative data

\begin{tabular}{llll}
\hline & CG & HPG & $p$ value \\
\hline Delta sCr (mmol/L) & $20(6-51)$ & $25(10-49)$ & 0.560 \\
Delta eGFR (ml/min) & $-6(-15-4)$ & $-3(-13-5)$ & 0.522 \\
AKI & $16(38 \%)$ & $19(46 \%)$ & 0.447 \\
Dialysis & $4(10 \%)$ & $3(7 \%)$ & 0.565 \\
Re-operation & $4(10 \%)$ & $1(3 \%)$ & 0.165 \\
Stroke & $3(8 \%)$ & $2(5 \%)$ & 0.687 \\
4 months follow-up & & & -7 to 5 \\
$\quad$ Change in GFR (ml/min) & $-9 \pm 12$ & $-5 \pm 16$ & 0.288 \\
$>10 \%$ decrease in GFR & $11(44 \%)$ & $9(39 \%)$ & 0.732 \\
30-day mortality & $3(7 \%)$ & $3(7 \%)$ & 1.000 \\
6-months mortality & $7(16 \%)$ & $8(18 \%)$ & 0.763 \\
\hline
\end{tabular}

Percentages are given as total within group. Continuous data are presented as mean \pm SD or median (interquartile min - max)

$A K I$ Acute kidney injury, CI confidence interval, AP Arterial pressure, eGFR Estimated glomerular filtration rate (calculated using the Cockroft-Gault formula), GFR Glomerular filtration rate (estimated by $\mathrm{Cr}$-EDTA clearance), $s \mathrm{Cr}$ Serum creatinine

${ }^{a}$ Percentages of total of patients at follow-up 


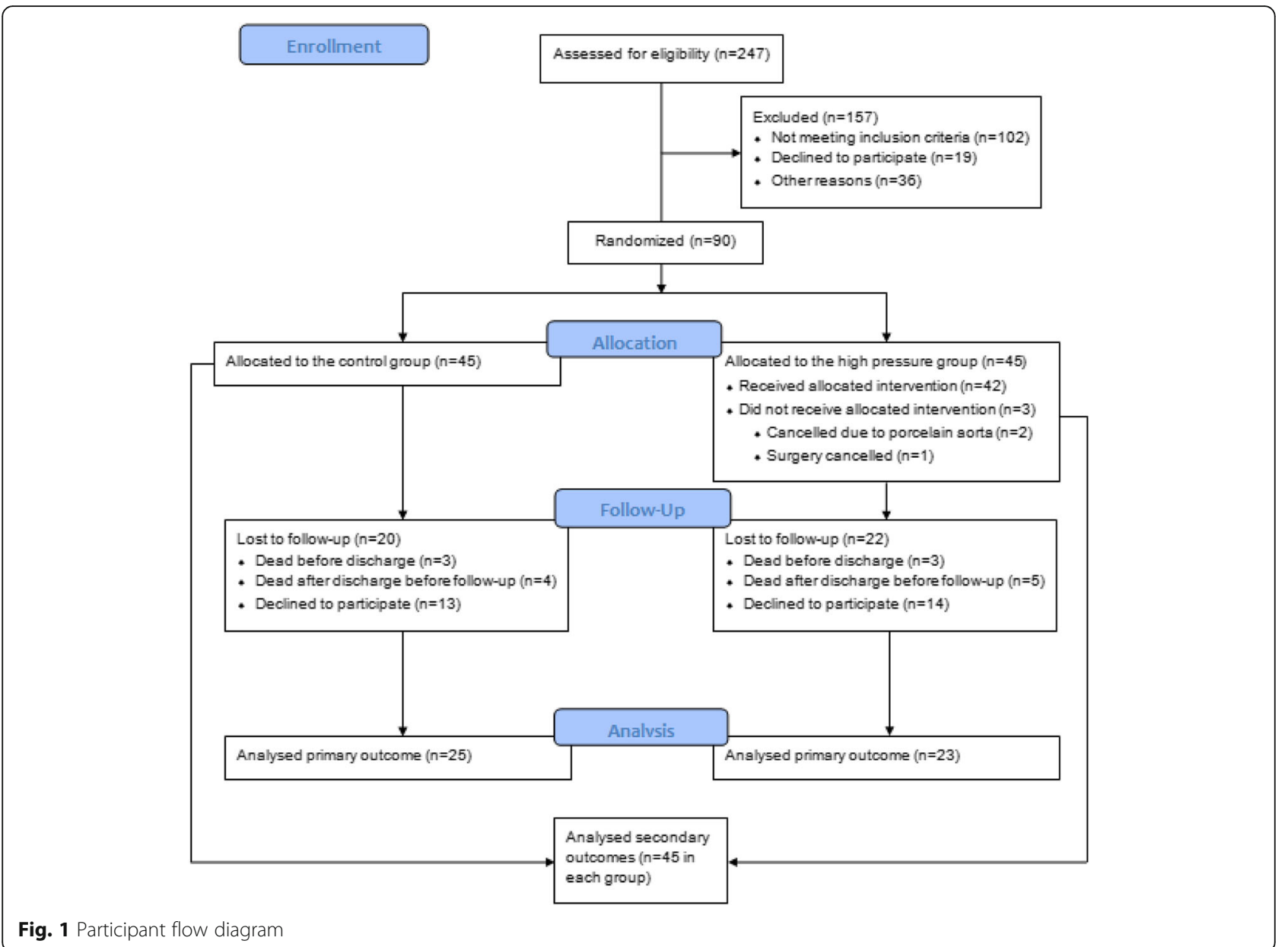

death was found between the groups. Data on mortality are shown in Table 3.

\section{Discussion}

We present a study conducted on cardiac surgery patients who had a high risk of developing AKI by using age $>70$ years and complex cardiac procedures as inclusion criteria. To our knowledge this is the first randomised study on the subject that have long-term renal outcome as the primary outcome, not only by looking at sCr or eGFR, but using measured GFR by using the $\mathrm{Cr}$ EDTA clearance method.

Table 4 uNGAL/creatinine changes from baseline ( $\mathrm{ng} / \mathrm{mL}$ )

\begin{tabular}{llll}
\hline & CG & HPG & $p$ value \\
\hline Preoperative (baseline) & $2(1-4)$ & $2(1-5)$ & 0.824 \\
Postoperative & $42(11-141)$ & $40(19-141)$ & 0.720 \\
$6 \mathrm{~h}$ & $8(4-58)$ & $10(2-40)$ & 0.768 \\
$18 \mathrm{~h}$ & $1(0-6)$ & $2(0-8)$ & 0.744 \\
$48 \mathrm{~h}$ & $3(0-6)$ & $4(1-6)$ & 0.596 \\
$120 \mathrm{~h}$ & $2(0-5)$ & $4(1-10)$ & 0.301 \\
\hline
\end{tabular}

Data is presented as median (interquartile min - max)
Table 5 Subanalysis of potential risk factors of AKI

\begin{tabular}{llll}
\hline & No-AKI & AKI & $p$ value \\
\hline $\mathrm{N}$ & 51 & 36 & \\
Male gender & $35(69 \%)$ & $29(80 \%)$ & 0.176 \\
Age & $76 \pm 4$ & $77 \pm 5$ & 0.098 \\
BMI $\left(\mathrm{kg} / \mathrm{m}^{2}\right)$ & $26 \pm 4$ & $28 \pm 5$ & 0.061 \\
EuroSCORE II & $3(2-5)$ & $3(2-4)$ & 0.865 \\
GFR & $73 \pm 28$ & $74 \pm 21$ & 0.867 \\
sCr & $87(75-104)$ & $85(75-109)$ & 0.836 \\
eGFR & $67 \pm 28$ & $75 \pm 24$ & 0.171 \\
AP & $54 \pm 8$ & $54 \pm 8$ & 0.802 \\
CPB time & $124 \pm 29$ & $138 \pm 37$ & 0.073 \\
Gentamicin administered & $38(83 \%)$ & $24(73 \%)$ & 0.155 \\
\hline
\end{tabular}

Percentages are given as total within AKI-group. Continuous data are presented as mean \pm SD or median (interquartile min - max)

$A K I$ Acute kidney injury, $A P$ Arterial pressure, $B M I$ Body mass index, $C P B$ Cardiopulmonary bypass, GFR Glomerular filtration rate, HCT Haematocrit, XC Aortic cross clamp 


\section{Long-term renal function}

A significant loss of GFR in both groups was observed at follow-up. Cardiac surgery should therefore be considered not only a risk factor for developing AKI but also a risk factor of permanent loss of renal function.

The primary finding of this study was that an intended increase in $\mathrm{AP}$ to $>60 \mathrm{mmHg}$ during $\mathrm{CPB}$ using norepinephrine did not result in any significant differences in GFR change from preoperative values to follow-up compared to lower intraoperative arterial pressures. This suggests that AP during $\mathrm{CPB}$ does not influence longterm renal function. However, overall measured GFR had decreased nearly $10 \%$ on average 4 months after surgery. Additionally, the development of AKI $<48 \mathrm{~h}$ postoperative was associated with a GFR reduction of $>10 \%$ at follow-up. Cardiac surgery should therefore be considered not only a risk factor for developing AKI but seems to result in a permanent loss of renal function in elderly patients undergoing complex cardiac surgery. This permanent loss of renal function has not been previously described and should be taken into consideration when planning surgery in this group of patients.

\section{Short-term renal function}

The secondary objective of this study was to investigate the relationship between AP during $\mathrm{CPB}$ and short-term renal function, defined by uNGAL/creatinine ratio and AKI.

By using inclusion criteria defining individuals in high risk of AKI, the study population had an AKI incidence of $41 \%$ in total. The reported incidence of AKI in the literature is $1-56 \%$ [7-9].

The incidence of AKI, estimated by the RIFLE criteria, was found to be equal in the two groups. The ratio of uNGAL/creatinine was also equal between the groups at all time-points. The uNGAL/creatinine ratio was significantly increased immediately postoperative and $6 \mathrm{~h}$ postoperative, indicating damage to the renal parenchyma due to intraoperative factors.

Only a few randomised studies exist investigating arterial pressure during $\mathrm{CPB}$ in relation to kidney injury as a primary outcome. One study used no age restrictions and included both combined and non-combined valve and CABG surgery [19]. Patients were randomised into three $\mathrm{AP}$ groups, ranging from an $\mathrm{AP}<60 \mathrm{mmHg}$ to $>70$ $\mathrm{mmHg}$. The primary endpoint was AKI defined by the RIFLE criteria. Eleven percent of the patients developed AKI. No differences regarding the incidence of AKI were found between the three groups. Another study used age $>70$ years as inclusion criterion as in our study, but only included CABG patients [20]. Patients were randomised into the same AP groups as in the above mentioned study. The incidence of AKI was equal between the groups. Both studies used the same lower AP threshold as in our study, i.e. $<60 \mathrm{mmHg}$.
A large randomized study conducted on 300 patients aimed for an even higher AP of $75-85 \mathrm{mmHg}$ in the control group [21]. The target AP in the control group was $50-60 \mathrm{mmHg}$ which is similar to the present study and the above mentioned studies. The outcome was AKI defined by changes in sCr. The rate of AKI in the groups was $17 \%$ vs. $17 \%(p=1)$. The mean AP reached in the control group was $60 \pm 6 \mathrm{mmHg}$, which is close to the AP in the control group of our study. This supports our findings and suggests that even very high AP during $\mathrm{CPB}$ does not protect the kidneys. At least not in terms of acute kidney injury.

A recent study with a more direct approach of measuring renal function by renal vein catheterization suggests that a higher flow than $2.4 \mathrm{~L} / \mathrm{min} / \mathrm{m}^{2}$ is beneficial for the kidneys [22]. The increased flow rates used were $2.7 \mathrm{~L} / \mathrm{min} / \mathrm{m}^{2}$ and $3.0 \mathrm{~L} / \mathrm{min} / \mathrm{m}^{2}$ which improved the renal oxygen supply/demand relationship by 14 and $30 \%$ respectively.

The above mentioned studies, in addition to our study, indicate that $\mathrm{AP}$ during $\mathrm{CPB}$ has no influence on the incidence of AKI on a broad range of patients and procedures. In addition, future randomised studies should also investigate the relationship between arterial flow and renal function.

\section{Limitations}

This study used an AP of $>60 \mathrm{mmHg}$ as the aim in the HPG. Therefore, it still remains unclear if even higher APs could decrease the risk of kidney injury.

The RIFLE criteria used to define AKI is based on $\mathrm{sCr}$, which varies depending on age, gender, muscle mass and race. This is partly adjusted for since the patient's own $\mathrm{sCr}$ is used as baseline and adjusted for age, gender and weight to calculate eGFR. However, in the postoperative period $\mathrm{sCr}$ can also vary considerably depending on the degree of haemodilution, making the values less reliable.

The number of patients lost to follow-up was high and the cohort size was relatively small. Although the numbers were the same in both groups there is still a risk of loss to follow-up bias.

It was not possible to perform a sample size calculation prior to the study since no previous data was available on GFR measurements on the patient category that was included in the study.

\section{Conclusion}

An intended $\mathrm{AP}>60 \mathrm{mmHg}$ during $\mathrm{CPB}$ did not seem to decrease the risk of acute or chronic kidney injury in patients $>70$ years of age undergoing concomitant cardiac surgical procedures. Cardiac surgery generally resulted in a substantial loss of renal function measured at follow-up 4 months postoperatively. 


\section{Abbreviations}

AKI: Acute kidney injury; AP: Arterial pressure; CG: Control group; CPB: Cardiopulmonary bypass; GFR: Glomerular filtration rate; HPG: High pressure group; ICU: Intensive care unit; NGAL: Neutrophil GelatinaseAssociated Lipocalin; sCr: Serum creatinine

\section{Acknowledgements}

Not applicable.

\section{Authors' contributions}

KK Patient inclusion, data collection, study design, data analysis and writing up of the first draft of the paper. JCN Study design, data analysis and writing up of the first draft of the paper. PO Study design, data analysis and writing up of the first draft of the paper. MEJ Patient inclusion, data collection, data analysis and writing up of the first draft of the paper. CHM Study design, data analysis and writing up of the first draft of the paper. JOC Study design and writing up of the first draft of the paper. HCA Study design, data analysis and writing up of the first draft of the paper. DAS Study design, data analysis and writing up of the first draft of the paper. All authors read and approved the final manuscript.

\section{Funding}

The corresponding author received funding from The Danish Heart Foundation covering his salary during the study period. No further funding has been received.

\section{Availability of data and materials}

The datasets used and analysed during the current study are available from the corresponding author on reasonable request.

\section{Ethics approval and consent to participate}

This study was approved by the Regional Scientific Committee of The Capital Region of Denmark. Reference number: 25396. All subjects included in the study gave a written consent after receiving written and oral information about the trial.

\section{Consent for publication}

Not applicable.

\section{Competing interests}

The authors declare that they have no competing interests.

\section{Author details}

'Department of Cardiothoracic Surgery, Copenhagen University Hospital, Rigshospitalet, Blegdamsvej 9, 2100 Copenhagen, Denmark. ${ }^{2}$ Department of Cardiothoracic Anaesthesiology, Copenhagen University Hospital, Rigshospitalet, Copenhagen, Denmark. ${ }^{3}$ Department of Clinical Physiology, Nuclear Medicine and PET, Copenhagen University Hospital, Rigshospitalet, Copenhagen, Denmark. ${ }^{4}$ Department of Hepatology, Copenhagen University Hospital, Rigshospitalet, Copenhagen, Denmark.

Received: 25 March 2019 Accepted: 3 June 2019

Published online: 13 June 2019

\section{References}

1. Coca SG, Yusuf B, Shlipak MG, Garg AX, Parikh CR. Long-term risk of mortality and other adverse outcomes after acute kidney injury: a systematic review and meta-analysis. Am J Kidney Dis. 2009;53:961-73.

2. Hobson CE, Yavas S, Segal MS, Schold JD, Tribble CG, Layon AJ, et al. Acute kidney injury is associated with increased long-term mortality after cardiothoracic surgery. Circulation. 2009;1 19:2444-53.

3. Howell NJ, Freemantle N, Bonser RS, Graham TR, Mascaro J, Rooney SJ, et al. Subtle changes in renal function are associated with differences in late survival following adult cardiac surgery. Eur I Cardiothorac Surg. 2012;41:e38-42.

4. Lassnigg A, Schmidlin D, Mouhieddine M, Bachmann LM, Druml W, Bauer P, et al. Minimal changes of serum creatinine predict prognosis in patients after cardiothoracic surgery: a prospective cohort study. J Am Soc Nephrol. 2004;15:1597-605.

5. Li SY, Chen JY, Yang WC, Chuang CL. Acute kidney injury network classification predicts in-hospital and long-term mortality in patients undergoing elective coronary artery bypass grafting surgery. Eur J Cardiothorac Surg. 2011;39:323-8.
6. Litmathe J, Kurt M, Feindt P, Gams E, Boeken U. The impact of pre- and postoperative renal dysfunction on outcome of patients undergoing coronary artery bypass grafting (CABG). Thorac Cardiovasc Surg. 2009;57:460-3.

7. Chertow GM, Levy EM, Hammermeister KE, Grover F, Daley J. Independent association between acute renal failure and mortality following cardiac surgery. Am J Med. 1998;104:343-8.

8. Karkouti K, Wijeysundera DN, Yau TM, Callum JL, Cheng DC, Crowther M, et al. Acute kidney injury after cardiac surgery: focus on modifiable risk factors. Circulation. 2009:119:495-502.

9. Ristikankare A, Poyhia R, Kuitunen A, Skrifvars M, Hammainen P, Salmenpera $M$, et al. Serum cystatin $C$ in elderly cardiac surgery patients. Ann Thorac Surg. 2010;89:689-94.

10. Lamy A, Devereaux PJ, Prabhakaran D, Taggart DP, Hu S, Paolasso E, et al. Off-pump or on-pump coronary-artery bypass grafting at 30 days. N Engl J Med. 2012;366:1489-97.

11. Nigwekar SU, Kandula P, Hix JK, Thakar CV. Off-pump coronary artery bypass surgery and acute kidney injury: a meta-analysis of randomized and observational studies. Am J Kidney Dis. 2009;54:413-23.

12. Seabra VF, Alobaidi S, Balk EM, Poon AH, Jaber BL. Off-pump coronary artery bypass surgery and acute kidney injury: a meta-analysis of randomized controlled trials. Clin J Am Soc Nephrol. 2010;5:1734-44.

13. Bartels C, Gerdes A, Babin-Ebell J, Beyersdorf F, Boeken U, Doenst T, et al. Cardiopulmonary bypass: evidence or experience based? J Thorac Cardiovasc Surg. 2002;124:20-7.

14. Fischer UM, Weissenberger WK, Warters RD, Geissler HJ, Allen SJ, Mehlhorn U. Impact of cardiopulmonary bypass management on Postcardiac surgery renal function. Perfusion. 2002;17:401-6.

15. Guyton AC, Hall JE. Textbook of medical physiology: Elsevier Saunders, United States of America; 2006. p. 323.

16. Koyner JL, Bennett MR, Worcester EM, Ma Q, Raman J, Jeevanandam V, et al. Urinary cystatin $\mathrm{C}$ as an early biomarker of acute kidney injury following adult cardiothoracic surgery. Kidney Int. 2008;74:1059-69.

17. Han WK, Wagener G, Zhu Y, Wang S, Lee HT. Urinary biomarkers in the early detection of acute kidney injury after cardiac surgery. Clin J Am Soc Nephrol. 2009:4:873-82.

18. Brochner-Mortensen J. A simple method for the determination of glomerular filtration rate. Scand J Clin Lab Invest. 1972;30:271-4.

19. Sirvinskas E, Andrejaitiene J, Raliene L, Nasvytis L, Karbonskiene A, Pilvinis V, et al. Cardiopulmonary bypass management and acute renal failure: risk factors and prognosis. Perfusion. 2008;23:323-7.

20. Sirvinskas $E$, Benetis $R$, Raliene $L$, Andrejaitiene J. The influence of mean arterial blood pressure during cardiopulmonary bypass on postoperative renal dysfunction in elderly patients. Perfusion. 2012;27:193-8.

21. Azau A, Markowicz P, Corbeau JJ, Cottlineau C, Moreau X, Baufreton C, et al. Increasing mean arterial pressure during cardiac surgery does not reduce the rate of postoperative acute kidney injury. Perfusion. 2014;29:496-504.

22. Lannemyr L, Bragadottir G, Hjärpe A, Redfors B, Ricksten SE. Impact of cardiopulmonary bypass flow on renal oxygenation in patients undergoing cardiac operations. Ann Thorac Surg. 2019;107:505-11.

\section{Publisher's Note}

Springer Nature remains neutral with regard to jurisdictional claims in published maps and institutional affiliations.

Ready to submit your research? Choose BMC and benefit from

- fast, convenient online submission

- thorough peer review by experienced researchers in your field

- rapid publication on acceptance

- support for research data, including large and complex data types

- gold Open Access which fosters wider collaboration and increased citations

- maximum visibility for your research: over $100 \mathrm{M}$ website views per year

At $\mathrm{BMC}$, research is always in progress.

Learn more biomedcentral.com/submissions 